\title{
La motivación de los alumnos polacos para el aprendizaje del español como lengua extranjera
}

\author{
Polish Students' Motivation to Learn Spanish as a Foreign \\ Language
}

\author{
Małgorzata Spychała-Wawrzyniak \\ Departament of Romance Studies, Adam Mickiewicz University, \\ Al. Niepodległości 4, 61-874 Poznań, Poland \\ e-mail: malgorzata.spychala@amu.edu.pl \\ Leonor Sagermann Bustinza \\ Departament of Romance Studies, Adam Mickiewicz University, \\ Al. Niepodległości 4, 61-874 Poznań, Poland \\ e-mail: leonor@amu.edu.pl
}

\begin{abstract}
Over the past several years the number of students learning Spanish as a foreign language has doubled in Poland. The present article is an attempt at answering the following questions: Why is Spanish so popular in Polish schools and what are the reasons for choosing this language by Polish students? The authors wish to analyze the situation from the point of view of two types of motivation: internal (integral) motivation and external (instrumental) motivation. The results of our study have been compared to the results of corresponding studies carried out among Polish students learning German. At the opening of our deliberations we present the definitions and typical features of motivation. Next the typology and origin of motivation is discussed, which incorporates both the cognitive and affective approach. Finally, we submit the results of a pilot study performed among Polish middle school and high school students who learn Spanish.
\end{abstract}

Keywords: Spanish language, motivation, internal (integral) motivation, external (instrumental) motivation 


\section{INTRODUCCIÓN}

El español es una lengua internacional, hablada por al menos 500 millones de personas. Es una lengua común ${ }^{1}$ de España y de muchos de los países hispanoamericanos sin olvidarse de Guinea Ecuatorial en África, que cuenta con casi 1.800.000 habitantes. También debemos subrayar que "Estados Unidos de América es el segundo país del mundo en número de hispanohablantes con una cifra que supera los 50 millones. Para casi 39 millones, el español es su lengua materna, lo que le otorga el estatus de segunda lengua en el país" (MECD, 2014, p. 205). Según los datos del Instituto Cervantes (2015), en el mundo "más de 21 millones de alumnos estudian español como lengua extranjera" (p. 5).

En los últimos años en Polonia ha crecido de manera excepcional el número de estudiantes que ha elegido el español como lengua extranjera (ELE) en las escuelas primarias y secundarias. Según los datos del Ministerio de Educación Polaco, en el año escolar 2010 había 31.782 alumnos de ELE y en el año 2015 había ya 86.513 alumnos de ELE (CIE, 2015). Las preguntas generales a las que pretendemos responder en este artículo son: ¿por qué el español es tan popular en las escuelas polacas? y ¿cuáles son los motivos de la elección de ELE por parte de los alumnos polacos? Queremos analizar esta situación desde el punto de vista de dos principales tipos de motivación: la motivación intrínseca o integradora y la motivación extrínseca o instrumental. Nos interesa comparar nuestras investigaciones con los resultados de las encuestas que se hizo entre los alumnos que estudian alemán en Polonia (Mackiewicz, 2014). Una de las conclusiones a las que llegó esta investigación es que, en el caso de los alumnos de alemán como lengua extranjera, domina la motivación extrínseca: resulta que el $65 \%$ de los encuestados aprendía alemán porque quería recibir una nota positiva de esta asignatura, mientras que solo el $11,3 \%$ de los alumnos quería conocer la cultura de los alemanes, austriacos o suizos.

En este artículo nos planteamos varias hipótesis. Una de ellas es que los estudiantes de ELE en Polonia, a diferencia de los alumnos de alemán, están influenciados por la motivación integradora o intrínseca, ya que la elección del español se une con un verdadero interés por esta lengua. Creemos que esta situación se debe sobre todo al novedoso carácter del español en las escuelas polacas (Spychała, 2015). Además, en la mayoría de los casos, los alumnos de las escuelas secundarias no habían tenido la posibilidad de aprender esta lengua en la escuela primaria. Esto significa que no se vieron perjudicados por una mala experiencia anterior con el español ${ }^{2}$. También creemos que la elección del español es tan exitosa porque a los

\footnotetext{
${ }^{1}$ Moreno Cabrera (2015, pp. 31-78) dedica en su libro titulado Los dominios del español. Guía del imperalismo lingüistico panhispánico espacio a explicar qué se entiende actualmente bajo el concepto de lengua común en el caso del español.

${ }^{2}$ En comparación con el inglés o el alemán, en Polonia todavía no hay una oferta de ELE bien desarrollada en las escuelas primarias. Según los datos del Ministerio de Educación Polaco (CIE, 2014),
} 
alumnos les gusta la cultura de los países hispanohablantes. Tampoco nos olvidamos de su carácter práctico: el número de hablantes de español en el mundo.

Al principio de nuestras reflexiones presentamos el concepto de la motivación, sobre todo, desde el punto de vista de la psicología educativa y la enseñanza de lenguas extranjeras. En las siguientes páginas nos centramos en los motivos que constituyen la principal fuente de las acciones que realizan los alumnos, teniendo en cuenta sus características tanto afectivas como cognitivas. Por último, presentamos el primer estudio pilotaje acerca de la motivación y los distintos motivos que se ha hecho entre los estudiantes de ELE de escuelas presecundarias y secundarias de Polonia.

\section{EL CONCEPTO DE LA MOTIVACIÓN Y SU PAPEL EN EL APRENDIZAJE DE LENGUAS EXTRANJERAS}

El término motivación proviene de latín motivus o motus que significa "la causa del movimiento". Debido a que existen numerosas teorías o enfoques que tratan de conceptualizar este término (sobre todo en el campo de psicología social), resulta bastante complicado definirlo. Sin embargo, la mayoría de los conceptos de la motivación ya elaborados tienen un punto común: se basan en explicar los mecanismos que arrancan, conducen, estimulan y determinan el comportamiento de una persona (Łukaszewski, 2003) ${ }^{3}$.

Reykowski (1977, p. 18) explica que la motivación es el proceso de una regulación psíquica de la que depende la dirección de las actitudes humanas. Y la realización de los objetivos se une directamente con la energía que uno quiere invertir para obtenerlos. Esta perspectiva está ligada a la visión de la motivación propuesta por Atkinson (1964), que la consideraba como una necesidad de logro o motivación de logro. Su compañero de investigación, McClelland (1989 [1985]), explica que la motivación:

se refiere por una parte a los propósitos conscientes, a pensamientos íntimos tales como me gustaría saber tocar el piano, quiero ser médico y estoy esforzándome por resolver este problema. Por otro lado, observando las conductas desde fuera, la motivación se refiere a las inferencias relativas a propósitos conscientes que hacemos a partir de la observación de las conductas. (p. 20)

en el curso escolar 2014-2015, 2.181.128 estudiantes estudiaban inglés, 127.204, alemán y 4.894, español. Debemos añadir que esta cantidad de alumnos de ELE en las escuelas primarias es comparable con el número de alumnos de francés (que era estudiado por 4.859 alumnos).

${ }^{3}$ Łukaszewski (2003, pp. 427-440) nos presenta un resumen de distintos enfoques o teorías de la motivación que han adoptado los psicólogos a lo largo de los años: el enfoque evolutivo, el enfoque psicodinámico, la teoría conductista, etc. 
En otras palabras, la motivación puede ser analizada desde el punto de vista de los verdaderos deseos de una persona y de los hechos que se puede observar en su conducta. Por ejemplo, un alumno nos dice que quiere aprender una determinada lengua extranjera, pero su postura o comportamiento posterior nos muestran que, en realidad, se siente obligado a estudiar y hablar esta lengua. Wilczyńska (1999, p. 107) añade que no todas las personas motivadas consiguen aprender una lengua extranjera y también hay personas sin motivación que llegan a aprenderla.

Según Dörnyei (2008 [2001]), en realidad la motivación "es un concepto abstracto e hipotético del que nos servimos para explicar por qué la gente piensa y se comporta como lo hace" (p. 17). Dicho de otro modo, nos interesan los antecedentes del comportamiento de una persona: sus causas y orígenes. También queremos analizar el tipo de esfuerzo que uno ha dedicado en su realización y la cantidad de tiempo que ha invertido en el proceso de realizar o conseguir algo (véase figura 1). El autor añade que no es fácil analizar los motivos de la gente para hacer o no hacer algo, ya que "la conducta humana es muy compleja, está sujeta a un sinfín de factores que van desde las necesidades físicas básicas (como por ejemplo comer), pasando por las necesidades de bienestar (como la seguridad económica) hasta llegar a un nivel más alto relativo a valores y creencias" (p. 25) ${ }^{4}$.

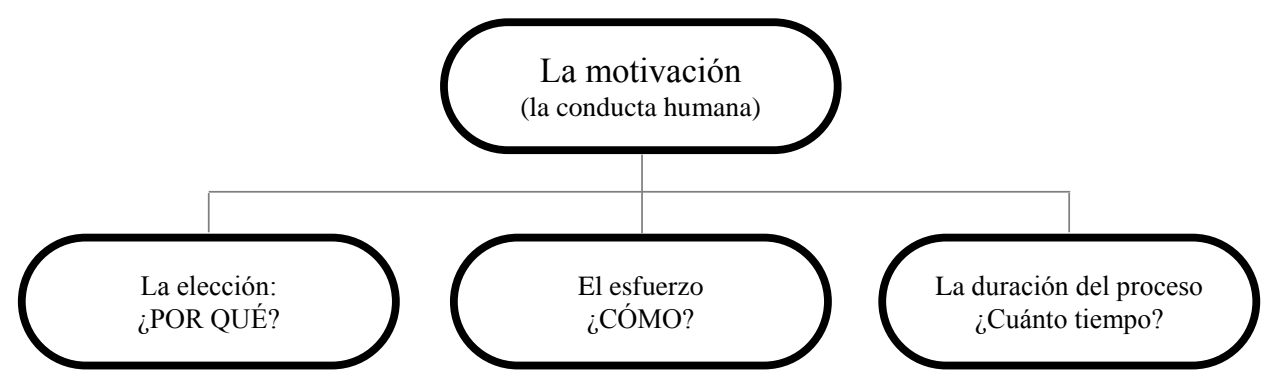

Fig. 1. Esquema de los factores que contribuyen en el análisis de la motivación según Dörnyei (2008 [2001])

La motivación se relaciona sobre todo con la personalidad y las características individuales de los alumnos. Existe también una unión entre las estrategias de aprendizaje y el rendimiento académico, la autoeficacia e incluso las posturas de los

\footnotetext{
${ }^{4}$ Maslow (2006 [1954]), creador de la jerarquía de las necesidades humanas, subraya que las necesidades fisiológicas son las más importantes en la teoría de la motivación y ocupan el primer puesto en la pirámide. En los siguientes escalafones de esta pirámide se encuentran las necesidades de: seguridad, afiliación, reconocimiento y autorrealización. Las capacidades cognitivas son las que sobre todo satisfacen las necesidades básicas y "cualquier peligro contra ellas, cualquier privación o bloqueo de su libre uso, tiene que de manera indirecta amenazar a las necesidades básicas" (Maslow, 2006 [1954], p. 72).
} 
estudiantes ante el fracaso escolar (Covington, 1984, 1992; Bandura, 2001; Crozier, 2001 [1997]; Schunk \& Zimmerman, 2008). Muchos de los estudiantes se sienten desmotivados porque creen que no "poseen la capacidad suficiente para superar los retos que les plantea su rol de estudiante" (Robles Mira, 1998, p. 27) ${ }^{5}$. Los investigadores también acentúan la importancia que tienen las experiencias previas de los alumnos que pueden motivarles o no para el futuro trabajo.

No obstante, los acontecimientos futuros también motivan. Muchos de los objetivos que pueden conseguirse están muy distantes. Un estudiante puede dedicar dos o tres años a la preparación de un examen; los estudiantes con dedicación parcial pueden pasar varios años asistiendo a clase en aulas congeladas durante las tardes de invierno antes de obtener los títulos que pretenden conseguir, abonando los costes financieros de su educación a medida que progresan [...]. El esfuerzo del presente está motivado por los resultados del futuro (Crozier, 2001 [1997], p. 188).

Las experiencias escolares previas positivas o negativas pueden relacionarse con el profesorado y sus capacidades de despertar en sus alumnos la curiosidad por una lengua extranjera. "La primera fuente de motivación para el aprendizaje es el afán natural por saber, que suele adoptar la forma de curiosidad. El ir aprendiendo motiva, a su vez, para nuevos aprendizajes. Dicho de otro modo: una enseñanza eficaz es de por sí motivadora" (Carrasco \& Basterretche Baignol, 2004 [1993], p. 46).

El estudiante también se siente motivado por el ambiente de la clase y lo que tiene algún vínculo con la asignatura fuera de la clase. Se trata de crear un entorno atractivo y positivo. Moreno García (2004) recuerda que, a veces, para un profesor puede ser complicado convertir este entorno en algo placentero, cuando las condiciones de trabajo son por sí mismas bastante difíciles. Sin embargo, la autora subraya que "cuando cerramos la puerta y nos encontramos ante la clase, lo más importante es que transmitamos a las personas presentes nuestra alegría por estar allí, que confiamos en sus posibilidades y que esperamos realizar progresos juntos" (p. 66).

Está claro que cuando en la clase se abordan temas interesantes para los alumnos, estos muestran mayor interés, son más activos y quieren continuar su aventura con esta asignatura. En cambio, si "los mismos sujetos, en interacciones de clase donde sus intervenciones iban destinadas a reproducir mecánicamente elementos lingüísticos descontextualizados, evidenciaban un menor compromiso cognitivo" (Lorenzo, 2006, p. 60) ${ }^{6}$.

Pfeiffer (2001) argumenta que, al hablar de la motivación en la enseñanza de lenguas, debemos distinguir entre la motivación que uno tiene (o no tiene) y el mismo proceso de motivar a alguien. La motivación en este caso es algo estable. Sin

\footnotetext{
${ }^{5}$ Véase Deci \& Ryan (2004 [2002]) y su modelo de la motivación humana.

${ }^{6}$ Una de las hipótesis que nos planteamos antes de hacer la investigación entre los alumnos polacos que eligen el español como segunda lengua extranjera en las escuelas secundarias era porque no querían seguir con el aprendizaje del alemán.
} 
embargo, el proceso de motivación tiene un carácter dinámico y activo. En otras palabras, si la motivación se considera el objetivo al cual queremos llegar, en el proceso de la motivación nos servimos de unas determinadas herramientas que nos ayudan a conseguirlo ${ }^{7}$.

Entre otras fuentes de la motivación, Carrasco \& Basterretche Baignol (2004 [1993], p. 50) enumeran las siguientes: el material didáctico, los métodos de enseñanza, la propia materia y su relación con los intereses y necesidades de los alumnos, la aprobación social, las herramientas lúdicas, la ambición de evitar fracasos, el deseo de distinguirse, etc. Concluyendo, la mayoría de los investigadores están de acuerdo que la motivación es uno de los factores más significativos en la enseñanza de lenguas extranjeras (Szałek, 2004 [1993]; Oxford, 1996; Gardner, 2010, etc.). Además, esta asignatura se diferencia de las otras porque implica "una alteración de la autoimagen, la adopción de nuevas conductas sociales y culturales y de nuevas formas del ser, por lo que produce un impacto importante en la naturaleza social del alumno" (Williams \& Burden, 2008 [1997], p. 122). En el caso del aprendizaje de una lengua extranjera el alumno se siente más motivado porque a través de la lengua llega a conocer, descubrir y entender la cultura o las culturas de la gente cuya lengua aprende . $^{8}$

\section{CARACTERÍSTICAS DE LA MOTIVACIÓN Y TIPOS DE MOTIVO: LOS ENFOQUES COGNITIVOS Y AFECTIVOS}

La motivación como manifestación psicológica dentro de un contexto social implica una alteración tanto de la dimensión cognitiva como afectiva. Según Williams \& Burden (2008 [1997]) el enfoque cognitivo "se centra en individuos que toman decisiones respecto a sus propias acciones" (p. 127). Se trata de mostrar una conducta consciente y con un determinado propósito (Hernández González \& Prieto Beracoechea, 2002). En cambio, el enfoque afectivo se relaciona con las emociones, sentimientos y la autoestima. Arnold \& Brown (2005) recuerdan que el aprendizaje es mucho más constructivo y eficaz si las dos dimensiones funcionan juntas. Goleman (1997 [1995]), autor del concepto de inteligencia emocional, subraya:

Ambas imágenes, pues, se presentan combinadas porque toda persona posee inteligencia cognitiva e inteligencia emocional, aunque lo cierto es que la inteligencia emocional aporta, con mucha diferencia, la clase de cualidades que más nos ayudan a convertirnos en auténticos seres humanos. (p. 84)

Además, las emociones pueden funcionar como un elemento que llena unos huecos informativos. Sin embargo, la curiosidad que es la fuente de la motivación se relaciona con el mecanismo cognitivo (Łukaszewski \& Doliński, 2003).

\footnotetext{
${ }^{7}$ Véase más adelante la distinción entre la motivación instrumental e integradora.

${ }^{8}$ Esta postura se vincula con la motivación integradora o intrínseca.
} 
La motivación es un concepto que tiene su estructura interna y empuja al hombre a actuar. Esta actividad puede ser causada por unos motivos (impulsos). Los motivos son diferentes en cada persona y, en general, influyen en su forma de percibir y evaluar la realidad (Rheinberg, 2006 [1995]).

Szałek (2004 [1993]) $)^{9}$ describe el motivo como la unión entre la causa y el efecto, o sea, el impulso que ha sido despertado por una necesidad para actuar de manera consciente y un propósito (véase figura 2).

NECESIDAD

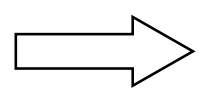

MOTIVO

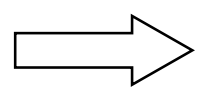

ACTIVIDAD

Fig. 2. Modelo de unión entre el motivo, la necesidad y la actividad (Szałek, 2004 [1993], p. 52)

Reykowski (1977) entiende el motivo como un deseo que es selectivo en la elección de las posibilidades que uno tiene. El objeto de los deseos funciona como un imán que emite un campo magnético. Cuando la motivación es negativa, el imán ejerce la fuerza de repulsión, mientras que cuando es positiva, se produce el efecto de atracción. El autor añade que uno de los factores que influye en los deseos es el saber prever las consecuencias de nuestros actos. Y los motivos nos llevan hacia lo que tiene consecuencias positivas y nos alejan de aquello cuyas efectos serán negativos.

Williams \& Burden (2008 [1997]) dividen la motivación en tres fases: primero, aparecen los motivos que empujan hacia la realización de una actividad; luego, las personas deciden invertir tiempo, energía en emprenderla; y, por último, hay que ser consecuente con la decisión que se ha tomado (véase figura 3).
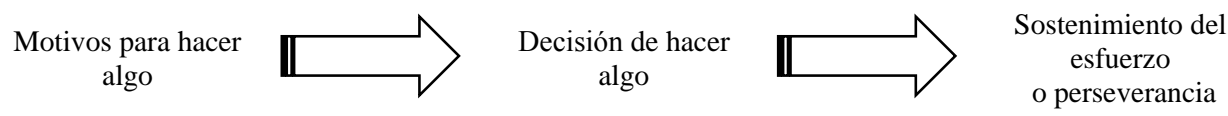

Fig. 3. El modelo de motivación según Wiliams \& Burden (2008 [1997], p. 129)

Debemos añadir que las decisiones que uno toma para realizar una actividad dentro de un contexto dependen de varios elementos que pueden ser de carácter interno o externo ${ }^{10}$.

\footnotetext{
${ }^{9}$ Szałek (2004 [1993]) elabora su concepto del motivo basándose en varios autores, como Wasiljewa (1981), Figarski (1984) o Dziekoński (1988).

${ }^{10}$ Hay que subrayar que la división entre los motivos internos y externos es más simple y más popular en la psicología de la motivación. De ahí viene la división entre la motivación intrínseca y extrínseca.
} 
Existen varias tipologías de la motivación y de los motivos. Szałek (2004 [1993]) propone una organización jerárquica (véase figura 4) donde en la parte superior se encuentran dos tipos de motivación: primaria y secundaria. La primera se relaciona con la adquisición de la lengua materna para poder comunicar las necesidades básicas (por ejemplo, la comida, bebida, etc.). La segunda, ya no tan fuerte, se vincula con el aprendizaje de una lengua extranjera. Este proceso puede ser positivo o negativo. En el primer caso distinguimos entonces dos tipos de motivación: la integradora y la instrumental (Gardner \& Lambert, 1972; Gardner, 2010). Veamos las siguientes definiciones:

Orientación integradora: refleja una predisposición positiva hacia el grupo de la L2 y el deseo de interactuar e incluso llegar a parecerse a miembros de esa comunidad valorados positivamente.

Orientación instrumental: en este caso el aprendizaje del idioma se asocia eminentemente con los potenciales beneficios pragmáticos que pueden obtenerse si se domina la L2, como por ejemplo optar a mejores puestos de trabajo, a un salario más alto. (Dörnyei, 2008 [2001], p. 36)

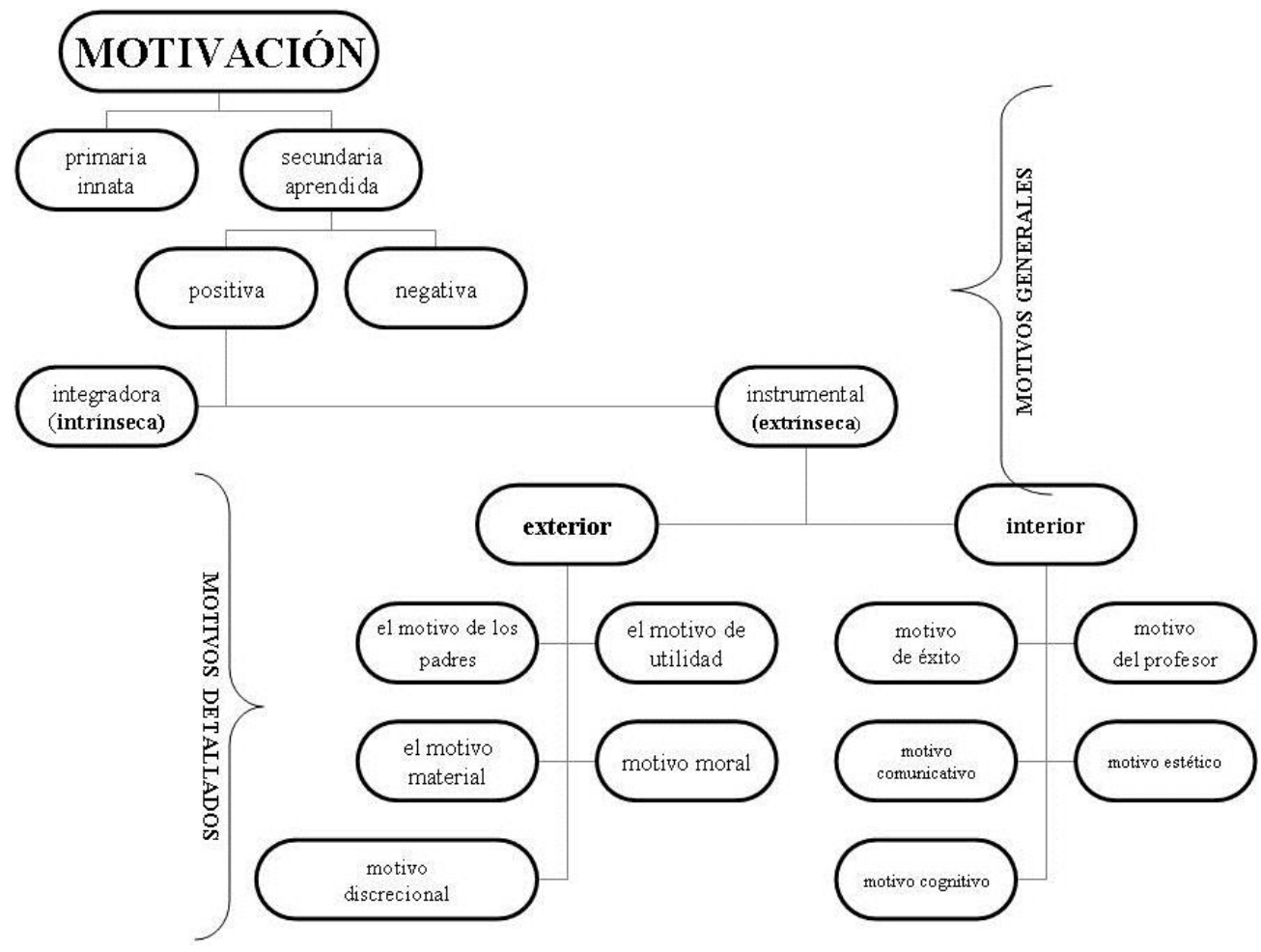

Fig. 4. Tipología de la motivación según Szałek (2004 [1993], p. 58) 
En otras palabras, la motivación integradora se produce cuando el alumno está interesado en conocer otras culturas y se asocia con la motivación intrínseca donde aparte de los motivos personales del alumno también destaca más el camino por el cual se llega a la meta. Se trata de realizar algo sin mucho esfuerzo, con interés e intención, de manera espontánea (Szałek, 2004 [1993]; Łukaszewski \& Doliński, 2003). Cuando el alumno aprende una lengua porque quiere conseguir, por ejemplo, un empleo mejor, en este caso hablamos de motivación instrumental. El aprendizaje de la lengua se convierte entonces en un instrumento que sirve para llegar a la meta. Entre los motivos que provocan la motivación extrínseca exterior, podemos enumerar, por ejemplo, el motivo de los padres, un motivo material, el motivo de utilidad, obligación o reconocimiento. Entre los motivos de motivación extrínseca interior, Szałek (2004 [1993]) distingue los siguientes motivos: de éxito, comunicativo que puede ser también el hecho de llevarse bien con el profesor, la personalidad del profesor, los métodos de enseñanza, etc.

Las investigaciones también demuestran que cuando uno tiene más autonomía en sus elecciones, se amplía la motivación intrínseca que se basa en realizar algo por la satisfacción inherente. Por eso, cuando los profesores son más controladores, reducen la curiosidad y las posibilidades de autodirección de sus alumnos. En caso de la motivación extrínseca, los alumnos en general obedecen a las regulaciones externas (Niemiec, Deci \& Ryan, 2010), intervienen la obligación y el esfuerzo por hacer algo (Łukaszewski \& Doliński, 2003).

Deci \& Ryan (2000, 2004 [2002]) unen el concepto de la motivación intrínseca con su teoría de autodeterminación (Self-Determination Theory). Es un enfoque que se basa en "la investigación de las tendencias inherentes del crecimiento de las personas y de las necesidades psicológicas innatas que son la base de su automotivación y de la integración de la personalidad, así como de las condiciones en que se anidan estos procesos positivos" (Deci \& Ryan, 2000, p. 2). Los autores también incluyen en su teoría una postura que expresa la falta de intención de hacer algo, o sea, la desmotivación. Esta postura de pasividad se manifiesta sobre todo debido a los sentimientos de carencia de las capacidades de realizar algo (Deci \& Ryan, 2004 [2002], p. 2) ${ }^{11}$. La motivación negativa también puede relacionarse con el contexto exterior del alumno (por ejemplo: los padres, los compañeros) y los elementos organizativos que pueden ser las condiciones del aprendizaje, por ejem-

${ }^{11}$ Deci \& Ryan (2004 [2002], pp. 16-18) elaboraron un modelo de la autodeterminación donde incluyen distintos tipos de motivaciones: DESMOTIVACIÓN (No regulación): no se regula la conducta (hay pasividad); MOTIVACIÓN EXTRÍNSECA que aporta cuatro regulaciones: externa (para recibir los premios o evitar los castigos), introyectada (para evitar el sentimiento de culpa o vergüenza), identificada (para valorar la conducta con el fin realizar algo), integrada (para establecer la unión entre la conducta, las experiencias positivas y los objetivos personales); MOTIVACIÓN INTRÍNSECA que se produce gracias a la regulación intrínseca, o sea, por el propio interés. Es el prototipo de la conducta autónoma o autodeterminada. 
plo, que se imponga a los alumnos estudiar una lengua determinada, el horario de clases, etc. (Szałek, 2004 [1993]).

Resumiendo, la motivación es un concepto muy amplio que requiere un análisis muy profundo desde distintos puntos de vista. En el caso del aprendizaje de una lengua extranjera debemos tener en cuenta tanto la personalidad del alumno, como el entorno en el que se educa. También hemos visto que la motivación, considerada como un fenómeno abstracto, sin lugar a dudas es una concepción muy dinámica y en pleno desarrollo. Sin embargo, la visión que predomina en los estudios es la división entre la motivación intrínseca y la extrínseca. A continuación, presentamos los resultados del estudio que reflejan distintos motivos de los alumnos polacos para estudiar ELE.

\section{PRESENTACIÓN DE LOS RESULTADOS. FACTORES QUE MO- TIVAN A LOS ALUMNOS POLACOS PARA ESTUDIAR ESPAÑOL}

A finales de octubre de 2015 se realizó la encuesta entre los alumnos de las escuelas polacas de enseñanza secundaria ${ }^{12}$, aprendices de español como primera y segunda lengua extranjera ${ }^{13}$. El cuestionario contaba con 20 preguntas cerradas, abiertas y de selección múltiple. Sin embargo, solo la primera parte abordaba las preguntas relacionadas con la motivación. Para la realización de la encuesta optamos por la creación de un formato electrónico, en línea, que fue puesto a disposición de los visitantes de la página web ${ }^{14}$.

Tal como se ha mencionado al principio de este artículo, el objetivo de la investigación era obtener información sobre los motivos que incitaron a los alumnos a elegir el español como lengua extranjera.

\subsection{PERFIL DE LOS PARTICIPANTES DE LA ENCUESTA}

En la encuesta participaron 803 alumnos ${ }^{15}$, de los cuales el $21,17 \%$ eran de sexo masculino y el 78,83\%, de sexo femenino. El 88,2\% de los encuestados cursaba estudios secundarios superiores (liceum o technikum), mientras que el 11,5\% era de gimnazjum. Eso significa que la edad predominante de los participantes de la en-

\footnotetext{
${ }^{12}$ En el sistema educativo polaco actual, la enseñanza secundaria se divide en: gimnazjum, equivalente a un centro de Enseñanza Secundaria Obligatoria, y liceum o technikum, donde se cursan los estudios equivalentes al bachillerato español; cada una de estas etapas educativas dura tres años.

${ }^{13}$ En Polonia, en las escuelas secundarias el programa de estudios prevé la enseñanza de dos lenguas extranjeras.

${ }^{14}$ La encuesta se realizó con la ayuda de Comité Organizador de las Olimpiadas Nacionales de Español.

${ }^{15}$ Los encuestados, en su mayoría, participaban en las Olimpiadas de Español 2015-2016.
} 
cuesta vacilaba entre 16 y 19 años. Debemos añadir que la gran mayoría de los encuestados eran habitantes de ciudad, el $80,82 \%$, donde el 33,8\% era de ciudades grandes, de más de 500.000 habitantes y el 44,8\% de ciudades medianas, de entre 100.000 y 500.000 habitantes. En cuanto a la división, según el año escolar que cursaban, hay que subrayar que es muy similar. Resulta que el 30,39\% estaba en primer curso, el $30,26 \%$ y el $30,88 \%$ en segundo y tercer curso, respectivamente. Un $8,34 \%$ indicó estudiar de otra forma, a saber: en un círculo de interés de su escuela, en una academia de idiomas o de manera individual. Otro dato que es imprescindible en este estudio es el tiempo que los alumnos llevaban estudiando español: alrededor del $30 \%$ de los encuestados estudiaba esta lengua desde hacía dos (29,39\%) o tres $(28,64 \%)$ años; un $10,83 \%$ cuatro años, mientras que los que se encontraban en los extremos de uno y cuatro años, representaban el 15,94\% y el 15,19\%, respectivamente. En cuanto a las horas de ELE que recibían en sus centros de enseñanza, constatamos que un $63,14 \%$ de ellos tenía entre una y tres horas ${ }^{16}$ de español por semana, donde un 44,58\% recibía dos horas de clase por semana. Un 13,69\% declaró tener más de seis horas de clase cada semana ${ }^{17}$. Debido a que uno de los factores que se relaciona con la motivación es el trabajo autónomo del alumno, también queríamos obtener información acerca del tiempo que los participantes dedicaban al aprendizaje del español fuera de la escuela. Resulta que el 11,37\% recibía entre una y dos horas de clases particulares por semana; el 5,54\% tenía entre dos y cuatro horas de clase semanales en escuelas de idiomas. La gran mayoría se basaba únicamente en lo que les proporcionaba el centro de estudios y su trabajo individual. El $68,64 \%$ declaraba dedicar entre una y dos horas por semana al estudio del español en casa. Resulta que, en cuanto al aspecto de las horas adicionales de estudio de las lenguas extrajeras en cuestión, en el caso de los estudiantes de alemán, tan solo un $16 \%$ indicó tener clases particulares o estudiar solo en casa (Mackiewicz, 2014, p. 90), mientras que la mayoría de los alumnos de español señaló que dedicaba por lo menos una o dos horas por semana al estudio del español en su domicilio.

\section{2. ¿MOTIVACIÓN EXTRÍNSECA O INTRÍNSECA? ANÁLISIS DE LOS RESULTADOS}

Por qué los alumnos escogieron el español como lengua de estudio es una de las interrogantes de más peso en nuestro cuestionario ${ }^{18}$. Esta pregunta tenía un carácter

\footnotetext{
${ }^{16}$ En el sistema polaco una hora de clase equivale a 45 minutos. En la encuesta, se explicitó que al hablar de horas de clase en los centros de enseñanza, se trataba de un equivalente de 45 minutos por hora lectiva.

${ }^{17}$ En la encuesta participaron también alumnos de secciones bilingües: son los que declararon tener más de cinco horas de español por semana.

${ }^{18}$ Los encuestados tenían la libertad de dejar en blanco algunas preguntas abiertas.
} 
semiabierto, ya que propusimos a los encuestados que escogieran hasta tres respuestas de un listado, como también les dimos la posibilidad de indicar otra causa. Los resultados obtenidos indican que prevalece la motivación integradora (intrínseca) relacionada con el gusto por la melodía de la lengua $(69,99 \%)$, seguida de la instrumental (extrínseca) por el hecho de ser la segunda lengua más hablada del mundo $(47,70 \%)$ y por no querer estudiar alemán $(44,96 \%)$; mucha menor importancia se dio en este aspecto al ruso y a otras lenguas románicas (véanse tabla 1 y figura 5).

Tabla 1. Razones por las cuales los alumnos polacos escogieron el español en su escuela

\begin{tabular}{|l|c|c|}
\hline \multicolumn{1}{|c|}{ Escogí estudiar español porque... } & \% & $\begin{array}{c}\text { Tipo de motivación } \\
\text { Intrínseca (I)/ Extrín- } \\
\text { seca (E) }\end{array}$ \\
\hline 1. Me lo recomendaron mis familiares y/o amigos & 13,95 & E \\
\hline 2. Me gusta el sonido de esa lengua & $\mathbf{6 9 , 9 9}$ & I \\
\hline 3. No quería estudiar alemán & $\mathbf{4 4 , 9 6}$ & E \\
\hline 4. No quería estudiar ruso & 4,86 & E \\
\hline 5. No quería estudiar francés & 6,72 & E \\
\hline 6. No quería estudiar italiano & 1,49 & E \\
\hline 7. No quería estudiar otra lengua & 1,49 & E \\
\hline 8. Quería estudiar una lengua románica & 11,58 & I \\
\hline 9. Me gustaba ver series hispanohablantes & 13,82 & I \\
\hline 10. Me gustaba oír música hispanohablante & 22,04 & I/E \\
\hline 11. Había estado en España (por ej. de vacaciones) & 17,81 & E \\
\hline $\begin{array}{l}\text { 12. Había oído decir que en mi futura escuela había buenos } \\
\text { profesores }\end{array}$ & 4,98 & I/E \\
\hline 13. Es la segunda lengua más usada en el mundo & $\mathbf{4 7 , 7 0}$ & E \\
\hline $\begin{array}{l}\text { 14. En los E.E. U.U. es la segunda lengua más usada, después } \\
\text { del inglés }\end{array}$ & 16,69 & E \\
\hline $\begin{array}{l}\text { 15. Tengo relaciones familiares con algún país hispanohablante } \\
\text { (por ej. mis padres, otros familiares) }\end{array}$ & 3,99 & \\
\hline
\end{tabular}

Además, en el caso de por qué los alumnos optaron por estudiar el español, muchos de los encuestados dieron explicaciones adicionales, entre las cuales se repetía con frecuencia la fascinación por la lengua y cultura, unida al deseo de viajar para conocer, estudiar o vivir en España u otros países hispanohablantes. Sin duda, en la mayoría de los casos la motivación intrínseca se entrelaza a la extrínseca. Otras

${ }^{19}$ En este caso consideramos que factores tanto internos como externos pueden influir en la decisión del alumno. 


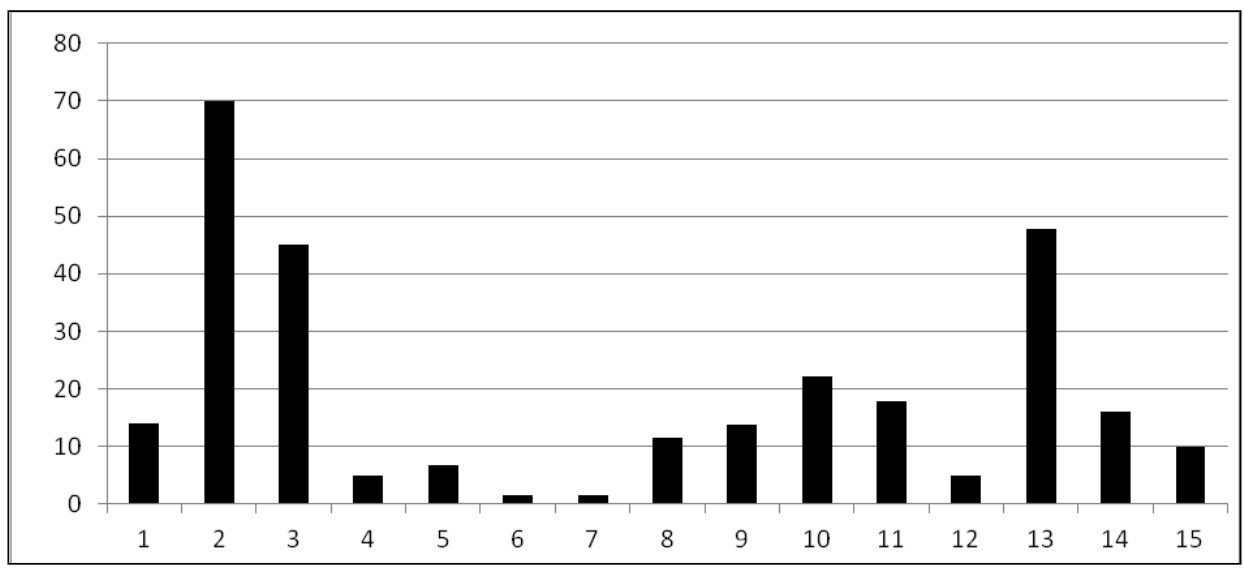

Fig. 5. Porcentaje de las razones por las cuales los alumnos escogieron el español en su escuela. (Véanse los descriptores de las razones 1-15 en la tabla 1)

respuestas muestran la madurez de sus autores, en cuanto al sentido práctico de conocer una lengua extranjera. Así, pudimos encontrar opiniones como la de que el conocimiento del español les resultará beneficioso para su futuro $(87,42 \%)$ : les facilitará comunicarse en países de habla hispana donde no siempre es posible comunicarse en inglés, encontrar trabajo, etc. Algunos quieren ser traductores, a otros les gusta el fútbol español y, en general, aprender idiomas.

La última cuestión que queremos exponer y analizar se relaciona con la importancia que tienen los motivos expuestos en una lista que los alumnos tuvieron la opción de valorar en una escala del 1 al 5 (según la escala de Likert), donde el número 1 significa que la respuesta sugerida no le motiva en absoluto, y el número 5 equivale a una motivación muy fuerte. La pregunta se formuló de la siguiente manera: “¿Qué es lo que más te motiva para estudiar español? Enumera tus respuestas desde la que más te motiva hasta la que menos; no es obligatorio escoger entre todos los elementos propuestos".

Presentamos los resultados porcentuales que suman las respuestas valoradas con un 4 y 5 , es decir, que explicitan una motivación fuerte (de acuerdo) o muy fuerte (totalmente de acuerdo).

El análisis de las respuestas obtenidas nos permite constatar que, para nuestros encuestados, entre aquellas opciones que caben en el marco de la motivación instrumental predominan: el deseo de obtener una buena calificación $(62,29 \%)$ y el de conseguir un buen trabajo entendido como un futuro lejano $(60,21 \%)$ o próximo $(61,82 \%)$, ya que algunos poseen la experiencia de trabajo en voluntariados o durante el verano. Los motivos extrínsecos que menor importancia tienen son la influencia de los padres $(12,01 \%)$, compañeros $(8,39 \%) \mathrm{y}$, mucho menos, el miedo 
al profesor $(2,84 \%)$. Por otra parte, mucho más frecuentes fueron las respuestas vinculadas a la motivación integradora (intrínseca), tales como la realización de viajes a países hispanohablantes $(83,26 \%)$, la posibilidad de comunicarse con hablantes nativos de español $(81,18 \%)$ y la satisfacción personal por el hecho de dominar esa lengua extranjera $(79,30 \%)^{20}$.

Tabla 2. Listado de motivos para el aprendizaje del español de los alumnos polacos

\begin{tabular}{|c|c|c|}
\hline Motivo & $\begin{array}{c}\text { Suma porcentual de respuestas } \\
\text { valoradas con un } 4 \text { (de acuerdo) } \\
\text { y } 5 \text { (totalmente de acuerdo) } \\
{[\%]}\end{array}$ & $\begin{array}{c}\text { Tipo de motivación } \\
\text { Intrínseca (I)/ Extrínseca (E) }\end{array}$ \\
\hline 1. El deseo de obtener una buena nota & 62,29 & $\mathbf{E}$ \\
\hline 2. La selectividad & 45,42 & $\mathrm{E}$ \\
\hline 3. Los futuros estudios superiores & 47,86 & $\mathrm{I} / \mathrm{E}^{21}$ \\
\hline $\begin{array}{l}\text { 4. La posibilidad de conocer la cultura } \\
\text { de países hispanohablantes }\end{array}$ & 63,96 & $\mathbf{I}$ \\
\hline 5. Los viajes a países hispanohablantes & 83,26 & $\mathbf{I}$ \\
\hline 6. El futuro trabajo profesional & 60,21 & $\mathbf{E}$ \\
\hline $\begin{array}{l}\text { 7. El uso del idioma en internet (Face- } \\
\text { book, Twitter u otros) }\end{array}$ & 43,22 & $\mathrm{I}$ \\
\hline 8. Ver la TV, películas en español & 49,12 & $\mathrm{I}$ \\
\hline $\begin{array}{l}\text { 9. La posibilidad de comunicarme con } \\
\text { personas hispanohablantes }\end{array}$ & 81,18 & I \\
\hline $\begin{array}{l}\text { 10. Quiero aprender esta lengua para mi } \\
\text { satisfacción personal }\end{array}$ & 79,30 & $\mathbf{I}$ \\
\hline $\begin{array}{l}\text { 11. Quiero participar en las Olimpiadas } \\
\text { de Español }\end{array}$ & 36 & I \\
\hline 12. Mi profesor/a & 35,55 & $\mathrm{E}$ \\
\hline 13. El hecho de evitar un suspenso & 39,72 & $\mathrm{E}$ \\
\hline 14. La influencia de mis padres & 12,01 & $\mathrm{E}$ \\
\hline 15. La influencia de mis compañeros & 8,39 & $\mathrm{E}$ \\
\hline 16. Mi personalidad (rasgos de carácter) & 49,37 & I \\
\hline 17. El deseo de conseguir un buen trabajo & 61,82 & $\mathbf{E}$ \\
\hline 18. El miedo al profesor & 2,84 & $\mathrm{E}$ \\
\hline
\end{tabular}

${ }^{20}$ Por motivos de la limitación del artículo no presentamos datos que relacionan distintas variables. Tampoco presentamos datos que revelan la actitud de los alumnos hacia los profesores de ELE, sus métodos o el material didáctico, ya que esta parte de la investigación será presentada en un análisis más amplio realizado en un futuro próximo por M. Spychała-Wawrzyniak. Sin embargo, analizando las respuestas valoradas con un 5 (totalmente de acuerdo), notamos que los alumnos $(41,16 \%)$ valoran mucho más los materiales preparados por los profesores que los manuales de ELE que tienen a su disposición en la clase $(17,94 \%)$.

${ }^{21}$ En este caso consideramos que factores tanto internos como externos pueden influir en la decisión del alumno. 


\section{CONCLUSIONES}

Concluyendo, en relación con las hipótesis que nos hemos planteado al principio de este trabajo podemos evidenciar que en los alumnos de ELE en Polonia dominan las emociones muy positivas, disfrutan aprendiendo español y sienten bastante interés por la cultura de los hispanohablantes (motivación intrínseca).

Si comparamos las respuestas de los alumnos de ELE con los datos obtenidos por Mackiewicz (2014, p. 90) en su estudio sobre la motivación de los alumnos polacos que estudian alemán ${ }^{22}$, vemos que hay algunos puntos en común, pero que los resultados son muy diferentes: tan solo el $20,2 \%$ señaló que le gustaba la lengua, el $7,1 \%$ indicó que eligió el alemán para no estudiar otra lengua, el 4,3\% se dejó influenciar por sus amigos, mientras que el $54,3 \%$ se vio obligado a elegir ese idioma en su centro educativo. Podemos observar que en la mayoría de los casos prima el motivo instrumental y son pocos aquellos que tomaron su decisión a causa de la motivación intrínseca. Las respuestas ${ }^{23}$ indicaban que dominaban los motivos relacionados con el hecho de obtener una buena nota de esa materia (más del $43 \%$ ), seguidos del motivo práctico de que esa lengua será necesaria en un contexto laboral (alrededor del 37\%). La necesidad comunicativa, en tanto que motivo integrador, fue indicada por un $35 \%$ de sus participantes, mientras que los motivos vinculados a una actitud abierta hacia diferentes elementos culturales (libros, películas, etc.) fue señalada tan solo por un $10 \%$ de los encuestados, frente a un $49,12 \%$ en el caso de los alumnos que estudian español.

Cabe recordar que en el caso de los alumnos de ELE casi el 70\% de ellos eligió el español porque les gusta cómo suena esta lengua. Sin embargo, también debemos subrayar que casi el $45 \%$ de los alumnos optó por el español porque no quería estudiar alemán. Lo que confirma que las experiencias negativas anteriores influyeron en sus posteriores elecciones. El análisis de las variables muestra que la mayoría de los alumnos empezó a aprender español en la escuela secundaria. Los resultados también confirmaron nuestra hipótesis de que los alumnos (casi el 48\%) eligieron el español debido al gran número de usuarios de esta lengua en el mundo.

En cuanto a los motivos de carácter externo e interno, podemos constatar que, a diferencia de los alumnos de alemán, los estudiantes de ELE se sienten mucho más atraídos por los viajes y por comunicarse con los hispanohablantes (motivación in-

\footnotetext{
${ }^{22}$ En la encuesta realizada por Mackiewicz (2014) participaron 1.779 alumnos. Según los datos del Ministerio polaco (2014), el alemán era aprendido por 1.527.699 alumnos en las escuelas secundarias, mientras que el español lo estudiaban 72.963 alumnos.

${ }^{23}$ Los resultados expuestos por Mackiewicz, a los que hacemos referencia en este apartado, también se basan en un listado de afirmaciones, donde los encuestados podían elegir estar muy de acuerdo o no estar de acuerdo en absoluto.
} 
trínseca) que por recibir una buena nota o por los exámenes finales (motivación extrínseca). Casi el 80\% confirmó que aprendía español por su satisfacción personal. Asimismo, los encuestados son conscientes del valor práctico que tiene el español en nuestros tiempos, hacia un 60\% vincula el hecho de dominar el español con la posibilidad de obtener un buen trabajo en el futuro. 


\section{BIBLIOGRAFÍA}

Arnold, J. \& Brown, D. H. (1999). A Map of the Terrain. En: J. Arnold (Ed.), Affect in Language Learning (pp. 1-24). New York: Cambridge University Press.

Atkinson, J. W. (1964). An Introduction to Motivation. Princeton, NY: Van Nostrand.

Bandura, A. (2001). Social cognitive theory of mass communication. Media Psychology, 3, 265-298.

Carrasco, J. B. \& Basterretche Baignol, J. (2004 [1993]). Técnicas y recursos para motivar a los alumnos. Madrid: Rialp.

Covington, M. V. (1984). The motive of self-worth. En: R. E. Ames \& C. Ames (Eds.), Motivation in Education: Student Motivation (vol. 1, pp. 77-113). San Diego: Academic Press.

Crozier, R. W. (2001 [1997]). Diferencias individuales en el aprendizaje: Personalidad y rendimiento escolar (trad. de P. Manzano). Madrid: Narcea.

CIE = Centrum Informatyczne Edukacji (2015). Nauczanie języka obcego, jako obowiązkowego w szkołach według typów i kategorii uczniów w roku szkolnym 2015/2016 wg SIO stan na 30.09.2015 r. [30/05/2016].

Deci, E. L. \& Ryan, R. M. (2000). La teoría de la autodeterminación y la facilitación de la motivación intrínseca, el desarrollo social, y el bienestar. American Psychologist, 55 (1), 68-78. Disponible en https://selfdeterminationtheory.org/SDT/documents/2000_RyanDeci_Spanish AmPsych.pdf [14/01/2016].

- (2004 [2002]). Handbook of Self-determination Research. Rochester, NY: The University of Rochester Press.

Dörnyei, Z. (2008 [2001]). Estrategias de motivación en el aula de lenguas (trad. de E. Álvarez de la Miyar). Barcelona: UOC.

Dziekoński, M. (1988). Wpływ motywacji na uczenie się. Język rosyjski, 3, 152-157.

Figarski, W. (1984). Wyznaczniki powodzenia w szkolnej nauce języka rosyjskiego. Warszawa: WSiP.

Gardner, R. C. \& Lambert, W. E. (1972). Motivational Variables in Second Language Acquisition. En: R. C. Gardner \& W. Lambert (Eds.), Attitudes and motivation in second language learning (pp. 119-216). Rowley, MA: Newbury House.

Gardner, R. C. (2010). Motivation and Second Language Acquisition: The Socio-educational Model. New York: Peter Lang.

Goleman, D. (1997 [1995]). Inteligencia emocional (trad. de D. González Raga \& F. Mora). Barcelona: Kairós.

Hernández González, M. \& Prieto Beracoechea, C. A. (2002). Un acercamiento a la motivación. En: M. Hernández González (Ed.), Motivación animal y humana (pp. 3-20). México DF: El manual moderno.

Instituto Cervantes (2015). El español: Una lengua viva. Informe 2015. Disponible en http://eldiae.es/wp-content/uploads/2015/06/espanol_lengua-viva_20151.pdf [14/01/2016].

Lorenzo, F. (2006). Motivación y segundas lenguas. Madrid: Arco Libros (Cuadernos de didáctica del español LE).

Łukaszewski, W. (2003). Motywacja w najważniejszych systemach teoretycznych. En: J. Strelau (Ed.), Psychologia. Podręcznik akademicki (pp. 427-440). Gdańsk: GWP.

Łukaszewski, W. \& Doliński, D. (2003). Mechanizmy leżące u podstaw motywacji. En: J. Strelau (Ed.), Psychologia. Podręcznik akademicki (pp. 441-468). Gdańsk: GWP.

Mackiewicz, M. (2014). Wiedza kulturowa i rozwój kompetencji interkulturowej jako cele i motywy uczących się języka niemieckiego. Języki obce w szkole, 3, 88-96.

Maslow, A. (2006 [1954]). Motywacja i osobowość (trad. de J. Radzicki) Warszawa: PWN. 
McClelland, D. C. (1989 [1985]). Estudio de la motivación humana (trad. de G. Solana). Madrid: Narcea.

MECD = Ministerio de Educación, Cultura y Deporte (2014). El mundo estudia español. 2014. Disponible en http://www.mecd.gob.es/dctm/redele/Material-RedEle/el-mundo-estudia-espanol/ el-mundo-estudia-espanol2014.pdf?documentId=0901e72b81c71bd2 [14/01/2016].

Moreno Cabrera, J. C. (2015). Los dominios del español. Guía del imperialismo lingüístico panhispánico. Madrid: Síntesis.

Moreno García, C. (2004). La enseñanza de español como lengua extranjera en un contexto escolar. Un enfoque intercultural de la enseñanza de la lengua. Madrid: Catarata.

Niemiec, C. P., Ryan, R. M. \& Deci, E. L. (2010). Self-determination theory and the relation of autonomy to self-regulatory processes and personality development. En: R. H. Hoyle (Ed.), Handbook of personality and self-regulation (pp. 169-191). Malden, MA: Blackwell Publishing.

Pfeiffer, W. (2001). Nauka języków obcych. Od praktyki do praktyki. Poznań: Wagros.

Reykowski, J. (1977). Z zagadnień psychologii motywacji. Warszawa: Wydawnictwa Szkolne i Pedagogiczne.

Rheinberg, F. (2006 [1995]). Psychologia motywacji (trad. de J. Zychowicz). Kraków: WAM.

Robles Mira, S. (1998). El éxito del fracaso. Estrategias para afrontar el fracaso escolar... y otros fracasos. Sevilla: MAD.

Oxford, R. (1996). New pathways of language learning motivation. En: R. Oxford (Ed.), Language Learning Motivation: Pathways to the New Century (pp. 1-8). Honolulu, Hawai: Second Language Teaching \& Curriculum Center.

Schunk, D. H. \& Zimmerman, B. J. (2008). Motivation and Self-regulated Learning: Theory, Research, and Applications. New York \& London: LEA.

Spychała, M. (2015). Kształcenie nauczycieli języka hiszpańskiego w Polsce i na świecie: wyzwania i potrzeby edukacyjne. En: M. Sowa, M. Mocarz-Kleindienst, U. Czyżewska (Eds.), Nauczanie języków obcych na potrzeby rynku pracy (pp. 367-379). Lublin: KUL.

Szałek, M. (2004 [1993]). Jak motywować uczniów do nauki języka obcego. Motywacja w teorii i praktyce. Poznań: Wagros.

Wasiljewa, M. M. (1981). Usłowija formirowanija motiwacii pri izuczenii inostrannogo jazyka. Inostrannyje języki w szkole 2, 29-34.

Wilczyńska, W. (1999). Uczyć się czy być nauczanym. O autonomii w przyswajaniu języka obcego. Warszawa \& Poznań: PWN.

Williams, M. \& Burden, R. L. (2008 [1997]). Psicología para profesores de idiomas. Enfoque del constructivismo social (trad. de A. Valero). Madrid: Edinumen. 